\title{
Chemo-physical evolution and microstructure features of lime treated soils
}

\author{
Giacomo Russo ${ }^{1, a}$, \\ ${ }^{1}$ Department of Civil and Mechanical Engineering, University of Cassino and Southern Lazio, Italy
}

\begin{abstract}
In the paper some results on the effects of chemo-physical evolution of clay-lime-water suspensions on the microstructure of a lime treated kaolin have been presented. A multi-scale investigation on the sedimentation behaviour of clay suspensions under different pore water chemistry has been developed highlighting the chemophysical mechanisms controlling particle arrangement and the soil fabric formation. The results evidenced the key role of ionic exchange in the short term on the microstructure features of the lime treated soil.
\end{abstract}

\section{Introduction}

The addition of lime to a clayey soil has a strong impact on the physical and mechanical properties in the short and long term after treatment [1-7]. Several studies on the basic lime-clay-reaction mechanisms have been widely reported in literature [8-14] allowing a better understanding of chemo-physical evolution of the system and microstructural features induced after the addition of lime [15-17].

When lime is added to the soil water system, either in the form of quicklime $(\mathrm{CaO})$ or as hydrated lime $\left(\mathrm{Ca}(\mathrm{OH})_{2}\right)$, a change in the pore water chemistry occurs. For quicklime the first reaction taking place is hydration reaction, highly exothermic, leading to the formation of hydrated lime (portlandite) in the soil water system. The dissociation reaction of the hydrated lime leads to an increase of the $\mathrm{pH}$ and to a high concentration of calcium ions in the pore water. The ions dissolved in the clay water system tend to counteract the charge on the basal face and lateral face sites of clay particles surface, controlling both the chemo-physical interactions and the arrangement of clay particles. The high $\mathrm{pH}$ environment induced by lime addition promotes the dissolution of the alumino-silicate constituents of clay minerals. Cementitious compounds, such as hydrated calcium silicates (C-S-H) or hydrated calcium aluminates (C-A$\mathrm{H})$, are formed as products of pozzolanic reactions between silica and alumina and lime.

The effects of the chemo-physical evolution of the clay-lime-water systems on microstructure play a key role in the mechanical improvement of lime treated soils. In the paper some results on the effects of chemophysical evolution of clay-lime-water suspensions on the microstructure of a lime treated kaolin have been presented. A multi-scale investigation on the sedimentation behaviour of clay suspensions under different pore water chemistry has been developed highlighting the chemo-physical mechanisms controlling particle arrangement and the soil fabric formation. Sedimentation behaviour of clay suspension is closely related to the electrochemical interactions acting at particle level [18-24]. Changes in the pore water chemistry induced by addition of lime affect the extent of attraction and repulsion forces among particles, controlling the microstructural features of the sediment

\footnotetext{
a Corresponding author: giarusso@unicas.it
}

formed from suspensions. The sedimentation tests are then a useful tool for understanding the effects of pore water chemistry on the microstructural features of the formaed soil skeleton.

In the paper the results of several sedimentation tests performed on lime treated kaolin suspensions have been reported and discussed. The chemo-physical evolution of the suspensions has also been studied at particle scale level. The electro-kinetic properties of clay particles governing the interaction forces have been inferred from Zeta-potential measurements. Soil fabric evolution and its effects on the physical properties have been investigated by means of Dynamic Light Scattering measurements. A discussion section has been finally devoted to the interpretation of results linking different scale level of the experimental analysis.

\section{Experimental procedures}

\subsection{Soil}

Speswhite kaolin was provided by Imerys Minerals UK. The specific gravity $\mathrm{G}_{\mathrm{s}}$ is 2.6 , and its surface area is 14 $\mathrm{m}^{2} / \mathrm{g}$. The $\mathrm{pH}$ value is 4.6. Atterberg limits are respectively $\mathrm{w}_{\mathrm{L}}=70 \%$ and $\mathrm{w}_{\mathrm{P}}=32 \%$, with a plasticity index IP equal to $38 \%$. The mineralogical composition is mainly formed by kaolinite clay minerals with a small amount of quartz and muscovite. No swelling clay phases were detected after the ethylene glycol treatment.

\subsection{Sedimentation tests}

The sedimentation behaviour of kaolin suspensions has been investigated as a function of lime content and cation valence. Suspensions were prepared in graduated cylinders with mixture of $50 \mathrm{~g}$ of dry kaolin at $100 \%$ of water content. Different amounts of $\mathrm{CaO}$ and $\mathrm{KOH}$ were added to reach the required $\mathrm{pH}$ and electrolytes concentrations. Additional water was added up to a initial volume of $1000 \mathrm{ml}$. The $\mathrm{pH}$ value was increased by adding $\mathrm{KOH}$. During the test the suspensions heights were monitored as a function of time.

Two typical curves can be identified (Figure 1) from sedimentation tests, depending on the degree of particles association in the suspension. Figure la shows the 
settling of a flocculated system, with the suspension height progressively reduced over time leaving a clear supernatant fluid. Figure $1 \mathrm{~b}$ shows a dispersed system maintaining its configuration over time. The height of the suspension in the latter case is not relevantly modified and a partition between the suspension height and a clear supernatant fluid is not well recognisable.

In a flocculated system three stages of the sedimentation process can be identified (Figure 2). During the initial stage (induction period), the electrochemical interactions [22] induce the aggregation from small clusters to aggregates depending on the surface charge distribution of particles. Its duration is linked to the degree of particles or aggregates association [25]. A slight translation of the interface between suspended solids and water can be appreciated in this stage. The clear separation between the suspended solids and the supernatant liquid indicates that sedimentation and self-weight consolidation stages are ongoing. The flocculated soil particles settle under gravity forming a deposit of increasing height which undergoes self-weight consolidation. Settling and self-weight consolidation take place simultaneously, as evidenced in Figure 2 with the time $t^{*}$. The soil formation line (Figure 2) delimitates the sedimentation and the self-weight consolidation regions and is characterised by a constant value of the void ratio $\mathrm{e}_{\mathrm{m}}$, the soil-formation void ratio, which represents the void ratio characterising the soil skeleton at zero effective stresses [26]. At time $t_{s}$, corresponding to the intersection between the soil formation line and the line representing the upper interface of the suspension, an abrupt reduction of settling velocity occurs, indicating the completion of the sedimentation stage $[23,27]$. During the subsequent self-weight consolidation stage the sediment reduces its height with a decreasing rate until the final height. During the self-weight consolidation the effective stresses gradually develop due to the mechanical interaction between aggregates [23, 28] until the soil skeleton is in equilibrium under its own weight. The duration $t_{f}$ of primary consolidation process generally lasts a time interval of two order of magnitudes larger than $t_{s}$, time necessary to complete the free settling stage [23, 27, 29].

\subsection{Microstructure analyses}

The Zeta potential measurements are based on the electrophoretic mobility of particles under an induced electric field. Mobility is then converted to zeta potential applying the Henry equation with the Smoluchovski approximation [30]. Diluted dispersions with $100 \mathrm{mg} / \mathrm{l}$ solid content and different concentration of calcium were prepared. The grain size fraction lesser than $1 \mu \mathrm{m}$ was extracted and used for zeta potential measurement. The $\mathrm{pH}$ of dilute dispersions were adjusted between 2 and 12.4 by adding $\mathrm{KOH}$. The measurement was performed at $25^{\circ} \mathrm{C}$ in a capillary cell (DTS1061) with Malvern Nano Zetasizer apparatus. For each sample at least 3 measurements were performed assuring the repeatability of the results.

The hydrodynamic size of soil particles was determined using dynamic light scattering (DLS)
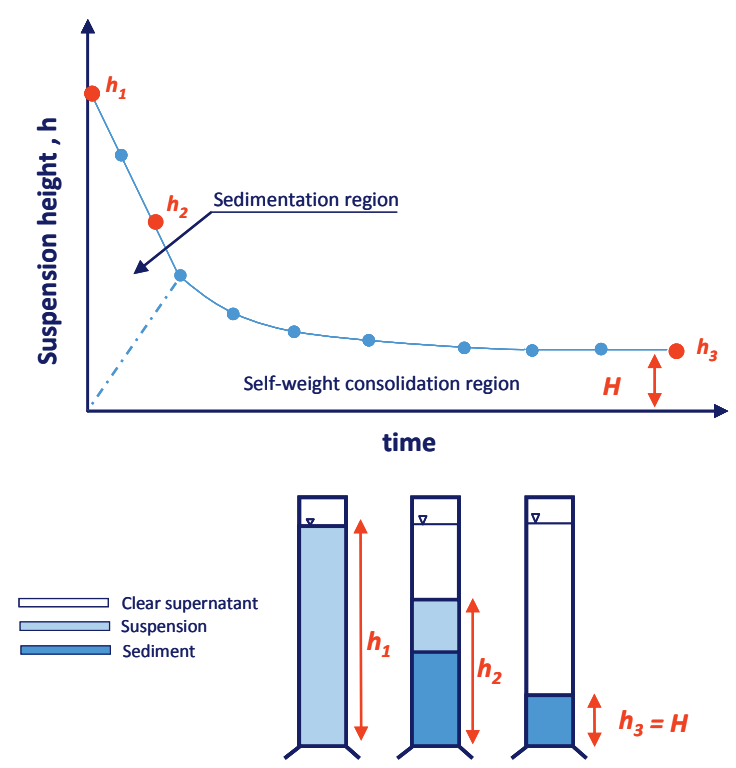

a
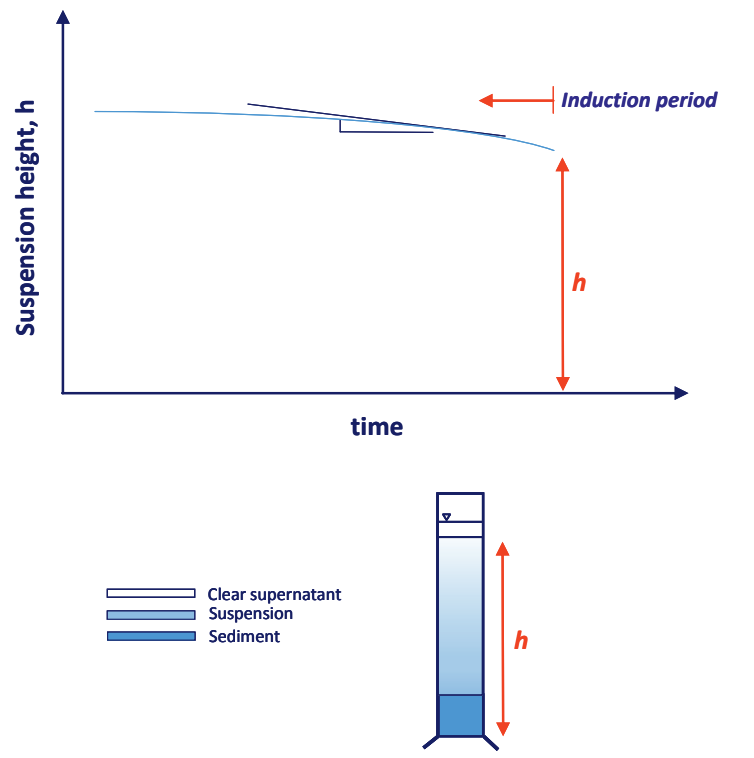

b

Figure 1. Sedimentation behaviour of suspensions a) flocculated system, b) dispersed system

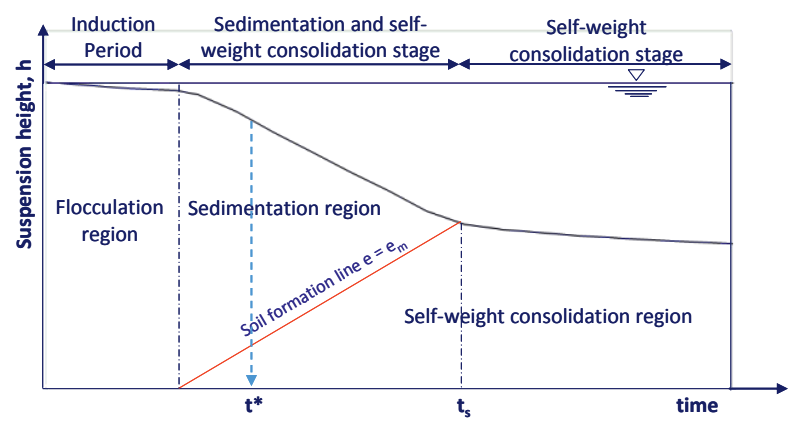

Figure 2. Stages of sedimentation process (after Vitale, 2016)

technique, based on the interaction between a set of particles and an incident radiation. Details of the technique are referred in [31].

The grain size fraction lesser than $1 \mu \mathrm{m}$ was extracted by dispersing about $10 \mathrm{~g}$ of sample in $1 \mathrm{~L}$ ultrapure water and centrifugation method. The suspension $(100 \mathrm{mg} / \mathrm{l})$ was prepared at different concentrations of $\mathrm{Ca}(\mathrm{OH})_{2}$ and 
KOH. Hydrodynamic size measurements were then performed at $25{ }^{\circ} \mathrm{C}$ and laser scattering at $173^{\circ}$ in a capillary cell with Malvern Nano Zetasizer apparatus.

\section{Results}

Sedimentation curves of kaolin suspensions prepared at increasing lime percentages are reported in Figure 3. The evolution of the suspension height is shown as a function of time with reference to two different time scales, namely the whole duration of the test (up to 13000 min, Figure 3a) and the initial stage of the test (up to 200 min, Figure $3 b$ ). Not treated kaolin suspension is characterised by a relatively long initial stage (induction period) during which the clayey particles show a negligible settling. A small percentage of lime $(1 \% \mathrm{CaO})$ promotes a more efficient particles association process due to alkaline environment and divalent cations, as showed by shorter induction period. It is noteworthy that no remarkable changes of the final sediment height were recorded (Figure 3a). As shown in Figure 3b, the higher amount of lime for $3 \% \mathrm{CaO}$ mixes promotes a higher degree of flocculation with respect to $1 \% \mathrm{CaO}$ mixes. As a consequence, a shorter induction period has been detected (Figure 3b) with an increase of the final sediment height after the self-weight consolidation stage (Figure 3a). No significant effects on the sedimentation behaviour and final suspension height were observed for samples treated with higher lime percentages (namely 5\% $\mathrm{CaO}$ and $7 \% \mathrm{CaO}$ ). Therefore, $3 \% \mathrm{CaO}$ can be regarded as the minimum amount of lime required to promote an effective aggregation of particle in the short term.

The influence of cation valence on the sedimentation characteristics of kaolin suspensions is shown in Figure 4. Sample prepared with $\mathrm{KOH}$ at $\mathrm{pH}=12.4$ showed a long induction period (Figure 4a), with particles dispersed in suspension and a not well recognizable sediment at the bottom of the cylinder (Figure $4 b$ ).

A further insight in the effects of pore water chemistry on the aggregation of kaolin particles has been highlighted by microstructural analyses results. In Figure 5 the zeta potential measurements of not treated and lime treated kaolin suspensions prepared at increasing $\mathrm{pH}$ have been presented. An increase of the zeta potential magnitude with increasing $\mathrm{pH}$ has been detected as consequence of deprotonation reactions respectively on the lateral and octahedral basal faces of kaolinite. The addition of lime (calcium hydroxide at increasing concentration) induces a decrease of the zeta potential decreases with increasing $\mathrm{pH}$. In particular, the reduction is sharp for $\mathrm{pH}$ higher than 9. Calcium undergoes hydrolysis at higher $\mathrm{pH}(\mathrm{pH}>10)$ leading to the formation of monovalent species [33, 34]. According to [14], the observed behaviour can be linked to the formation and specific adsorption of first hydrolysis product of calcium (i.e. $\mathrm{CaOH}^{+}$).

The evolution of the size of aggregated particle structure with time was monitored by Dynamic Light Scattering (DLS) measurements. For kaolin suspension in deionized water $(\mathrm{pH}=4.6)$ (Figure 6), the measured average size of aggregations increases with time as a
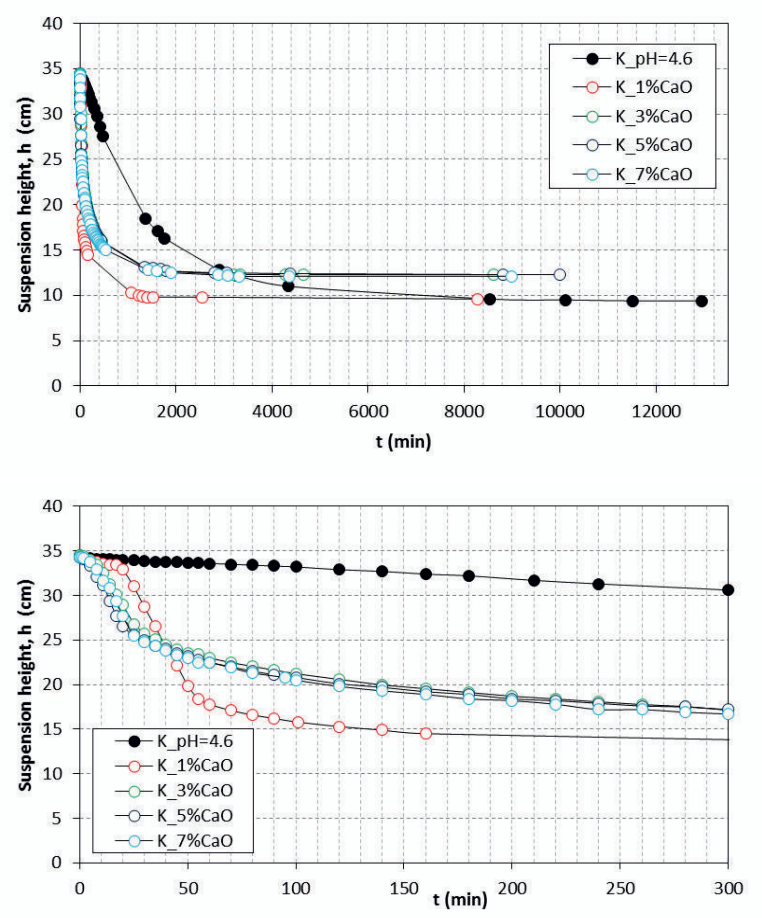

b

Figure 3. Sedimentation curves of increasing lime content suspensions: a) whole duration of the test, b) initial stage
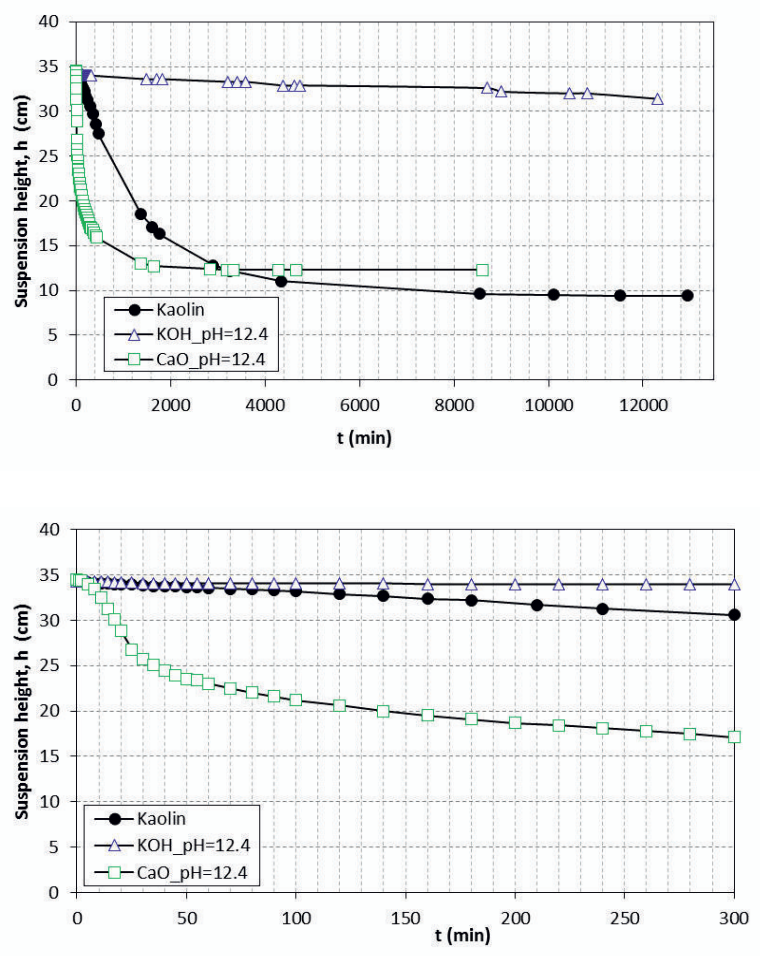

$\mathrm{b}$

Figure 4. Sedimentation curves of suspension prepared with different valence ions: a) whole duration of the test, b) initial stage

consequence of positively charged edge and negatively charged basal face mode of particle aggregation referred to as edge-to-face [35]. As the $\mathrm{pH}$ increased to 12.4 by adding $\mathrm{KOH}$, the size of aggregates is smaller and remains unchanged over time. The kaolinite particles are 
not flocculated and their mutual interaction is weak (i.e. dispersed state). The high negative surface charge, as indicated by higher zeta potential (Figure 5), increases the electrostatic repulsive forces preventing particles collisions and aggregations. The presence of calcium $\left(\mathrm{Ca}(\mathrm{OH})_{2}\right)$ and the alkaline environment $(\mathrm{pH}=12.4)$ favour the larger average size of kaolinite aggregates and a strongly flocculated structure. Calcium ions counteract the effect of higher surface charge and repulsive forces, promoting particles collisions and aggregations.

\section{Discussion}

A pH dependent surface charge behaviour of kaolin suspension was observed from zeta potential measurements. In acidic environment the interaction between particles is the result of Coulombian attractions between positively charged edges and negatively charged faces (edge-to-face arrangement). In alkaline environment the absolute value of zeta potential increases due to the increase of negative charges on the kaolinite edge surfaces (deprotonation reaction). The results of sedimentation test showed a flocculated behaviour of kaolin suspensions in deionized water at $\mathrm{pH}=4.6$, confirmed by DLS results highlighting the increase of the average aggregate size as a consequence of the edge-toface flocculation. The increase of $\mathrm{pH}$ provided by the addition of $\mathrm{KOH}$ induces a suspension stability. The repulsive forces between charged particles prevent flocculation, as confirmed by the constant size of kaolinite particles over time detected by DLS measurements.

The addition of lime induces a change in the pore water chemistry, with an increase of the $\mathrm{pH}$ and the divalent cation concentration, affecting the sedimentation behaviour of kaolin suspension. A larger decrease of the absolute value of the zeta potential (Figure 5) is the consequence of calcium adsorption at the surface of the negatively charged particles. The repulsive forces are no longer able to counteract the van der Waals attractions [36], and an increase of the flocculated aggregates size is detected, as showed by DLS measurements results.

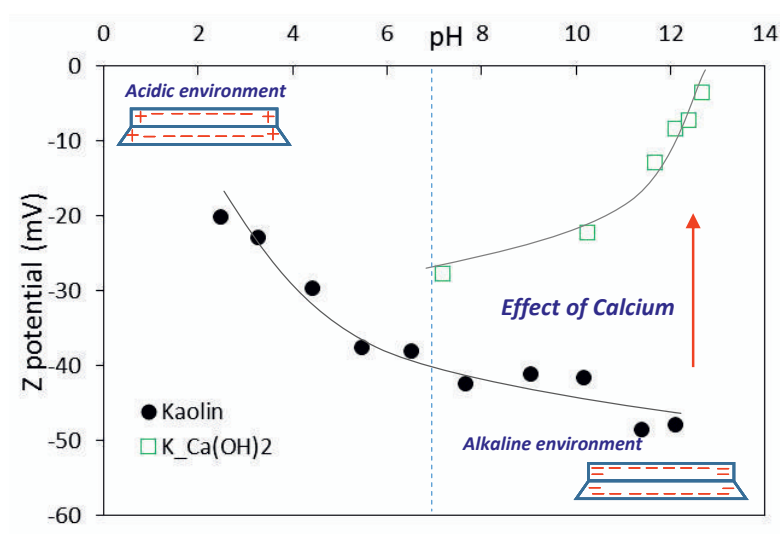

Figure 5. Zeta potential measurements of not treated and lime treated suspensions

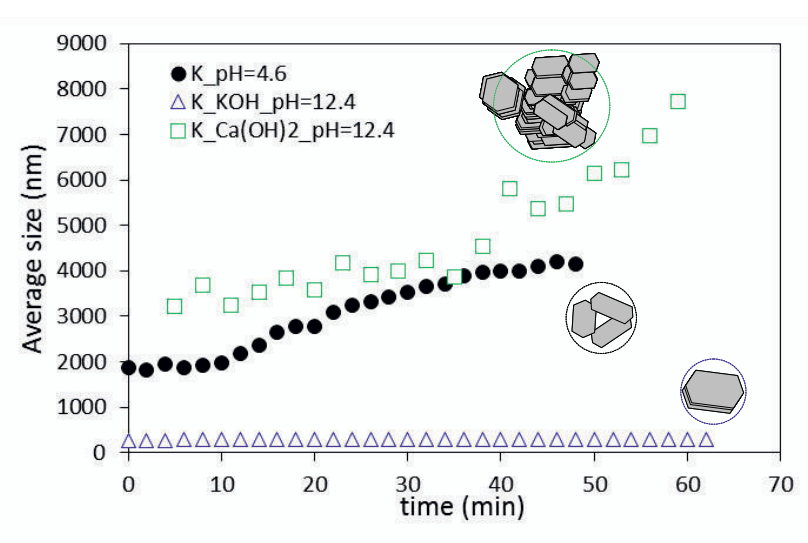

Figure 6. Evolution of aggregates size by Dynamic Light Scattering

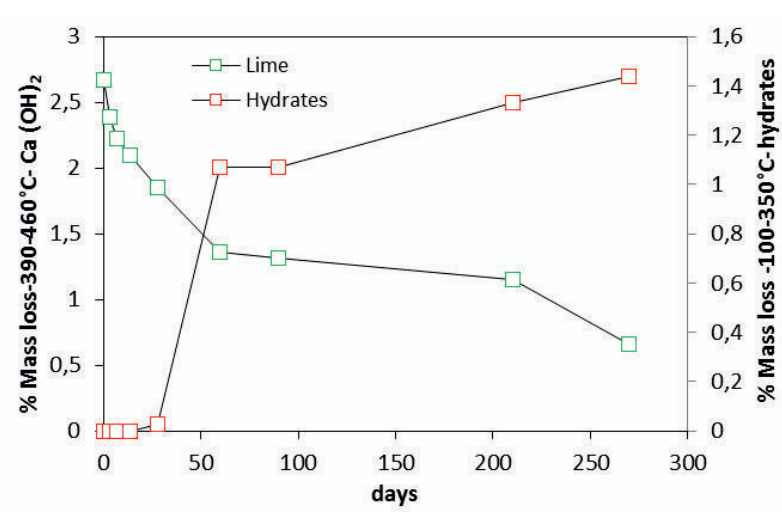

Figure 7. Termogravimetric analyses on $3 \% \mathrm{CaO}$ kaolin treated samples (after Vitale, 2016)

The aggregation of particles of lime treated suspensions can be considered not affected by the ongoing of pozzolanic reactions with reference to the time intervals analysed during the sedimentation tests (about 9 days). As reported by [31], thermo-gravimetric analyses performed on $3 \% \mathrm{CaO}$ treated kaolin samples showed a low reactivity in the short term, as showed in Figure 7 , where the mass losses of hydrated lime $\left(390^{\circ} \mathrm{C}\right.$ $\left.-460^{\circ} \mathrm{C}\right)$ and cementitious compounds $\left(110-350^{\circ} \mathrm{C}\right)$ after the treatment have been represented as function of time. A significant consumption of portlandite and formation of new cementitious phases has been detected only after times longer than 28 days.

The increase of the average dimensions of clay aggregates in saturated lime solution is consistent with the increase of the soil-formation void ratio $\mathrm{e}_{\mathrm{m}}$ determined from the sedimentation curves. The soil formation void ratio $\mathrm{e}_{\mathrm{m}}$, measured at the top of the sediments layer corresponds to the soil skeleton void ratio under zero effective stresses. Its value is representative of the soil skeleton void ratio induced only by the pore water chemistry. In order to estimate its value for each suspension, the end of sedimentation stage time $t_{s}$ and the corresponding thickness of the sediment $h_{s}$ were evaluated from the sedimentation curves. A lower limit of soil-formation void ratio $\mathrm{e}_{\mathrm{s}}$ can be inferred by considering that the total thickness of the solid matter $h_{z}$ (i.e. the material height) for each of the sedimentation tests is 
constant throughout the sedimentation/consolidation process [27], that is

$$
h_{z}=\frac{h_{0}}{1+e_{0}}=\frac{h_{s}}{1+e_{s}}=\text { constant }
$$

where $\mathrm{h}_{0}$ and $\mathrm{e}_{0}$ are respectively the initial height and the initial void ratio of the suspension. The value of $e_{m}$ must satisfy the following relationship:

$$
e_{m} \geq e_{s}=\frac{h_{s}}{h_{z}}-1
$$

Since for each treated sample the time to achieve full consolidation $t_{f}$ was found to be two order of magnitude larger than $t_{s}[27]$ the difference between the calculated $e_{s}$ and the soil-formation void ratio $\mathrm{e}_{\mathrm{m}}$ has been considered negligible. Therefore, $\mathrm{e}_{\mathrm{m}}$ was assumed as the representative value of void ratio when the soil skeleton is completely formed without any mechanical effect (i.e. zero effective stresses). The estimated values of $t_{s}$ and $h_{s}$ and the calculated values of $\mathrm{e}_{\mathrm{s}}$ for $1 \% \mathrm{CaO}$ and $3 \% \mathrm{CaO}$ mixes have been reported in Table 1 .

Table 1. Estimated and calculated values from sedimentation curves

\begin{tabular}{ccccccc}
\hline Test & $\begin{array}{c}\mathbf{e}_{\mathbf{0}} \\
(-)\end{array}$ & $\begin{array}{c}\mathbf{h}_{\mathbf{0}} \\
(\mathrm{cm})\end{array}$ & $\begin{array}{c}\mathrm{t}_{\mathrm{s}} \\
(\mathrm{min})\end{array}$ & $\begin{array}{c}\mathbf{h}_{\mathbf{s}} \\
(\mathrm{cm})\end{array}$ & $\begin{array}{l}\mathbf{e}_{\mathbf{s}} \\
(-)\end{array}$ & $\begin{array}{l}\mathbf{t}_{\mathbf{f}} \\
(\mathrm{min})\end{array}$ \\
\hline $\mathrm{K} \_1 \% \mathrm{CaO}$ & 50 & 34.5 & 52.5 & 19.1 & 27.3 & 1530 \\
$\mathrm{~K} \_3 \% \mathrm{CaO}$ & 50 & 34.5 & 25 & 28 & 40.4 & 2833 \\
$\mathrm{~K} \_5 \% \mathrm{CaO}$ & 50 & 34.5 & 20 & 27.5 & 39.7 & 2886 \\
\hline
\end{tabular}

The final height of the sediments after the soil skeleton formation, at the end of the tests, is affected by the pore water chemistry. The negative charge neutralization induced by the addition of lime causes a reduction of inter-particle repulsions promoting van der Waals attractions between particles. During the consolidation stage, the effective stresses increase inducing the reduction of the soil skeleton volume, due to the self-weight effect and the van der Waals attractions. The contribution of the attractive forces results in lower volume strains during consolidation, and thus higher sediment heights, as showed by lime treated suspensions which experience a consolidation stage characterized by lower settlements due to the higher contribution of van de Waals attractions.

\section{Conclusions}

In the paper some results on the effects of chemophysical evolution of clay-lime-water suspensions on the microstructure of a lime treated kaolin have been presented. A multi-scale investigation on the sedimentation behaviour of clay suspensions under different pore water chemistry has been developed highlighting the chemo-physical mechanisms controlling particle arrangement and the soil fabric formation.

The results evidenced the key role of ionic exchange in the short term in terms of microstructure features of the treated soil. No effects of pozzolanic reactions were overlapped to the observed behaviour due to the low reactivity of kaolinite. The arrangement of kaolin particles in suspension is strongly $\mathrm{pH}$ dependent, with a flocculated face to edge arrangement at $\mathrm{pH} 4.6$ turning to a dispersed one at higher $\mathrm{pH}$. The addition of calcium ions in suspension induces the formation of larger particles aggregates, formed by face to face stacking of particles grouped face to edge. The sedimentation behaviour in presence of calcium is consistent with the effects of particle arrangement, highlighting a shorter induction period, a faster settling stage and a shorter consolidation stage due to the aggregation induced by the pore water chemistry.

\section{Acknowledgments}

The Author is grateful to Dr. Enza Vitale and Dr. Dimitri Deneele for their valuable support during the experimental stage and for the helpful discussions during the interpretation of the results. The microstructural analyses were performed at Institut des Materiaux Jean Rouxel, Université de Nantes, France. A special thank to Prof. Guy Ouvrard for his support to the research.

\section{References}

1. G. R. Glenn, R. L. Handy, Highway Research Board, Washington, D.C. (1963)

2. H. Brandl, Proc. 10th Int. Conf. Soil Mech. Found. Eng., Stockholm, 3, 587-594, (1981)

3. F.G. Bell, Engineering Geology, 42, 223-237, (1996)

4. C.D.F. Rogers, S. Glendinning, In Lime Stabilisation, C.D.F. Rogers, S. Glendinning and N. Dixon (eds.), 99-112, Thomas Telford, (1996)

5. J. Locat, H. Tremblay, S. Leroueil, Canadian Geotechnical Journal 33 (4), 654-669, (1996).

6. P.V. Sivapullaiah, A. Sridharan, A.N. Ramesh, Canadian Geotechnical Journal 37:1358-1367, (2000)

7. H. Tremblay, S. Leroueil, J. Locat, Canadian Geotechnical Journal, 38: 567- 579, (2001)

8. J. L. Eades, R. E. Grim, Highway Research Board, Bulletin 262, pp.51-53, (1960)

9. S. Diamond, E.B. Kinter. Presentation at the 44th Annual Meeting, Highway Research Board, 92, Washington, (1965)

10. D.I. Boardman, S. Glendinning, C.D. Rogers, Geotechnique 50, No. 6, 533-543, (2001)

11. N. Maubec, Thése de doctorat, Faculté des sciences et des techniques, Université de Nantes (2010)

12. L. Delavernhe, Thèse de doctorat, Université de Nantes, (2011)

13. E. Pomakhina, D. Deneele, A. C. Gaillot, M. Paris, G. Ouvrard, Cement and Concrete Research, 14, 626-632, (2012)

14. Y. C. Chemeda, D. Deneele, G. E. Christidis, G. Ouvrard, Applied Clay Science, 107, 1-13, (2015) 
15. G. Russo, S. Dal Vecchio, G. Mascolo, In T. Schanz, ed. Experimental Unsaturated Soil Mechanics. Springer Berlin Heidelberg, pp. 49-56, (2007)

16. Z. Metelková, J. Boháč, R. Přikryl, I. Sedlářová, Applied Clay Science 61 (2012) 37-43, (2012)

17. G. Russo, G. Modoni, Géotechnique Letters, 3, pp.93-9, (2013)

18. K. Ma, A.C. Pierre, Clays and Clay Minerals, 40, 586-592, (1992)

19. K. Ma, A.C. Pierre, Clays and Clay Minerals, 47, 4, 522-526, (1999)

20. A.M. Palomino, J. C. Santamarina, Clay and Clay Minerals, Vol. 53, No. 3, 209-222, (2005)

21. A. Kaya, A.H. Oren, Y. Yukselen, Marine Georesources and Geotechnology, 24: 203-218, (2006)

22. G. Imai, Soils and Foundations, Vol. 20, No.2, Japanese Society of Soil Mechanics and Foundation Engineering 61-77, (1980)

23. G. Imai, Soils and Foundations, Vol. 21, No.1, Japanese Society of Soil Mechanics and Foundation Engineering 7-20, (1981)

24. A.S. Michaels, J.C. Bolger, Industrial Engineering Chemistry \& Fundamentals, 1, 24-33, (1962)
25. A. M. Palomino, S. E. Burns, J. C. Santamarina, Clays and Clay Minerals, Vol. 56, No. 6, 599-611, (2008)

26. V. Pane, $\mathrm{PhD}$ thesis, Department of Civil Engineering, University of Colorado, Boulder, (1985)

27. V. Pane, R. L.Schiffman, Géotechnique 47, No. 2, 273-288, (1997)

28. G. C. Sills, Phil. Trans. R. Soc. Lond., 356, $2515-$ 2534, (1998)

29. K. Been, G.C. Sills, Geotechnique, 31 (4), 519-535, (1981)

30. R.J. Hunter, Academic Press, New York, (1981)

31. E. Vitale, PhD thesis, University of Cassino and Southern Lazio, (2016)

32. E. Vitale, D. Deneele, G. Russo, G. Ouvrard, Applied Clay Science, in press, (2016)

33. P. Mpofu, J. Addai-Mensah, J. Ralston, J. Colloid Interface Sci. 261, 349-359, (2003)

34. P. Mpofu, J. Addai-Mensah, J. Ralston, International Journal of Mineral Processing 75, 155-171, (2005)

35. E. Tombacz, , M. Szekeres, Appl. Clay Sci. 34, 105124, (2006)

36. H. Van Olphen, John Wiley, (1977). 